\title{
Videolaryngoscopy Findings of the Vocal Health Program in Dysphonic Teachers in the Federal District, Brazil
}

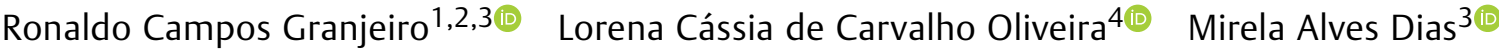 \\ Cristiane Ferraz de Oliveira ${ }^{3(0)}$ Glauce Mara Gomes Ferreira Oliveira ${ }^{30}$
}

1 Escola Superior de Ciências da Saúde, Brasília, DF, Brazil

${ }^{2}$ Hospital de Base do Distrito Federal, Brasília, Distrito Federal, Brazil

3 Governo do Distrito Federal, Gerência de Promoção à Saúde do Servidor,

Brasília, Distrito Federal, Brazil

${ }^{4}$ Department of Otorhinolaryngology, Hospital Estadual Materno-

Infantil Dr. Jurandir do Nascimento, Goiânia, GO, Brazil
Address for correspondence Cristiane Ferraz de Oliveira, MS, Governo do Distrito Federal, Gerência de Promoção à Saúde do Servidor, Setor Comercial Sul, Quadra 09, Edifício Parque Cidade Corporate, $1^{\circ}$ Subsolo, Torre A, Brasília, Distrito Federal, 70075-900, Brazil

(e-mail: crisferraz_usp@yahoo.com.br; mrldias9@gmail.com).

\begin{abstract}
Keywords

- laryngoscopy

- dysphonia

- laryngeal diseases

- school teachers

- promotion of health

- occupational health services

Introduction The high phonatory demand required of teachers is a direct cause of the onset of vocal symptoms and of the development of laryngeal disorders.

Objective To describe the findings of the laryngeal screening performed as part of the Vocal Health Program held in the Federal Distrcit of Brazil in 2014 and 2015.

Methods The study was performed with 361 dysphonic teachers from public schools who attended the laryngeal screening (videolaryngoscopy) part of the program. Data on anamnesis, the degree of dysphonia, the findings of the laryngeal screening, the referrals made after the laryngeal screening, and the result of the assessment of vocal aptitude for work were analyzed from the forms of each participating teacher.

Results The sample of the present study $(N=361)$ represents $18.23 \%$ of the 1,980 teachers that went through the vocal screening of the program in 2014 and 2015. In total, 98 (27.15\%) teachers presented mild dysphonia, 221 (61.22\%), moderate dysphonia, and 42, (11.63\%) severe dysphonia. Regarding the laryngeal screening (videolaryngoscopy exam), 269 teachers (74.52\%) presented laryngeal disorders, and the main ones found were vocal nodules (43.87\%), signs of laryngopharyngeal reflux (37.17\%), hourglass chink (18.22\%), vascular dysgenesis (18.22\%), midposterior triangular chink (9.67\%), and double chink (8.55\%).

Conclusion Laryngeal screening through videolaryngoscopy and auditory-perceptual screening of the voice as part of vocal health programs are essential to define the diagnosis and therapeutic conduct for teachers with dysphonia. Together with intervention activities, continuing education and adequate and accessible treatment, the periodic evaluation of vocal health can contribute to reduce absenteeism and improve the quality of life and of the voice of teachers.
\end{abstract}

received

December 15, 2020

accepted

March 25, 2021

published online

August 30, 2021
DOI https://doi.org/ 10.1055/s-0041-1733929. ISSN 1809-9777. (c) 2021. Fundação Otorrinolaringologia. All rights reserved.

This is an open access article published by Thieme under the terms of the Creative Commons Attribution-NonDerivative-NonCommercial-License, permitting copying and reproduction so long as the original work is given appropriate credit. Contents may not be used for commercial purposes, or adapted, remixed, transformed or built upon. (https://creativecommons.org/ licenses/by-nc-nd/4.0/)

Thieme Revinter Publicações Ltda., Rua do Matoso 170, Rio de Janeiro, RJ, CEP 20270-135, Brazil 


\section{Introduction}

The voice is one of the main forms of expression of human beings. In that sense, voice professionals stand out for having it as one of their main instruments of work. ${ }^{1}$ Vocal problems are commonly experienced in this group, which includes teachers, salespeople, singers, and other professionals. ${ }^{2}$

The prevalence of voice disorders in the general population is estimated to be between $6 \%$ and $15 \%$, although this percentage increases between $20 \%$ and $89 \%$ among teachers, ${ }^{3-6}$ who are disproportionately affected by voice disorders. In the United States, while teachers correspond to $4 \%$ of the population, they represent $20 \%$ of the patients with voice disorders, which demonstrates the relevance of the subject. A brazilian study ${ }^{7}$ shows that when comparing teachers with other professionals, the former present approximately two times the risk of developing voice disorders. Thefore, this establishes a high-risk status for this group of professionals when compared with others. ${ }^{7}$

The high phonatory demand required of teachers is a direct cause of the onset of vocal symptoms and of the development of laryngeal disorders. In other professions, even when there is some type of vocal abuse, the voice is naturally produced at a lower intensity, and, most of the time, phonatory overload is only occasional. Furthermore, these professionals do not teach lecture rooms full of students daily, as teachers do.

Among the vocal symptoms most reported by teachers, it is possible to highlight hoarseness, loss of voice, burning throat or throat irritation, dry throat, vocal fatigue and shortness of breath while talking, coughing, throat clearing, difficulty in emitting high-pitched sounds, and projecting the voice, vocal effort, phonation breaks, and weak vocal intensity. ${ }^{4,6,8-10}$

As for the laryngeal signs among dysphonic teachers diagnosed through videolaryngoscopy, a study ${ }^{11}$ showed $23.5 \%$ of cases of dysphonia with normal morphology, and $26.5 \%$ of cases with nodules, totalling $50 \%$ of occupational dysphonia. The other $50 \%$ were divided into $20 \%$ of cases of congenital lesions, in which the professional use of the voice could reveal these lesions, and $30 \%$ of cases of non-occupational dysphonia, such as allergic or infectious laryngitis and laryngopharyngeal reflux. ${ }^{11}$ These signs, as well as the symptoms, may cause impairment in communication, which affects social life and work activities. ${ }^{12}$ and can also cause to economic, personal, and social losses. ${ }^{2}$

Another important consequence related to work is the loss of working days. Studies ${ }^{13,14}$ have shown that $23 \%$ of teachers report absences from their professional activity due to vocal problems.

Only a third of the teachers with dysphonia seek specialist assistance, and less than half are aware of the possibility of performing voice therapy, believing that dysphonia is normal among teachers. ${ }^{14}$

Teachers usually fail to notice vocal changes, and often report that their voice has always had the same characteristics. Those who can observe important vocal changes search for specific treatments. Early diagnosis has shown to be beneficial, for it may not only reduce the chances of developing inadequate adjustments, but it can also reduce the impact of dysphonia in the medium and long terms. Thus, it's possible to see a reduction in the number of medical leaves, as well as a reduction in the duration of the treatment. ${ }^{5,13}$

Non-dysphonic teachers have more work opportunities, a factor that should be considered nowadays.

The literature on this topic is vast, but most researches are restricted to the analysis of answers contained in questionnaires filled out by teachers. Few studies ${ }^{15}$ cover vocal screening in the work environment and videolaryngoscopy exams for the diagnosis and preventive actions.

Therefore, the purpose of the present study was to describe the findings of the laryngeal screening performed as part of the Vocal Health Program (VHP) held in the Federal District of Brazil in 2014 and 2015.

\section{Method}

The present is a cross-sectional, retrospective, descriptive study performed using data collected from the VHP in 2014 and 2015, and it was approved by the ethics in research committee from Fundação de Ensino e Pesquisa em Ciências de Saúde (FEPECS) under number 61145416.1.0000.5553.

The findings presented were extracted from the assessment form of the teachers who participated.

The VHP, developed in the public school system of the Federal District, was organized in 3 stages. The first stage, performed in the schools during the weekly assembly of teachers, consisted of vocal screening through an auditoryperceptual analysis of the voice using RASAT (Rouquidão, Aspereza, Soprosidade, Astenia and Tensão) scale, the resonance system and the degree of dysphonia, as parameters; referral for a laryngeal screening of teachers who presented moderate and severe dysphonia, and of teachers with mild dysphonia who reported a previous history of laryngeal disorders (criteria established by the VHP itself); and a voice workshop. The second stage consisted of laryngeal screening (through the videolaryngoscopy exam) with subsequent referral for treatment (clinical, surgical, or vocal rehabilitation) or for complementary exams. In addition, the screened teachers were sent, as needed, to the third stage of the VHP, which consisted of guidance on vocal health or vocal experience workshops, since the VHP aims to prevent voice disorders and promote vocal health and does not include treatment or other complementary exams. ${ }^{16}$

The inclusion criteria for were: being a public school teacher, having dysphonia during vocal screening performed in schools, and, after being referred for laryngeal screening, having undergone videolaryngoscopy. Teachers who had an incomplete assessment form and teachers who presented previous professional vocal use restriction were excluded from this study. Data from the assessment form of the teachers who met the aforementioned criteria is herein presented.

The assessment form of each participating teacher included data on anamnesis, such as personal identification (name, 
gender, and age), professional activity (grades taught by the teachers and years of professional experience), lifestyle habits (smoking and alcohol intake), and vocal symptoms (voice complaints and duration of the main complaint); the degree of dysphonia (obtained through vocal screening performed at the schools); the findings of the laryngeal screening (videolaryngoscopy); referrals made after the laryngeal screening; and the result of the assessment of the vocal aptitude for work.

The laryngeal screening through the videolaryngoscopy exam was performed using a Hopkins autoclavable $70^{\circ}$ rigid endoscope (Karl Storz SE \& Co.), and a National Television Standards Committee (NTSC) / Phase Alternate Line (PAL) processing unit for a TRICAM SL II microcamera (Karl Storz SE \& Co.), IPM, SCB. After the laryngeal screening, the teachers received the videolaryngoscopy report, as well as a medical certificate and referrals, as needed.

The data collected were analyzed statistically, and they are herein presented descriptively or in graphs, using absolute and relative frequencies (in percentages).

\section{Result}

In 2014 and 2015, a total of 2,420 professionals from the Brazilian Federal District's public school system attended the VHP voice workshops. In the same period, the VHP performed the vocal screening of 1,980 teachers from the same public school system using auditory-perceptual analysis of voice.
After the vocal screening, 550 (27.78\%) teachers were referred for laryngeal screening (videolaryngoscopy) according to the criteria established by the VHP; 361 (65.54\%) attended the exam, and 189 (34.36\%) did not.

Therefore, the sample of the present study $(N=361)$ corrsponds to $18.23 \%$ of the 1,980 teachers screened by the VHP in 2014 and 2015.

Among the 361 (100\%) dysphonic teachers who composed the study sample, there was a female prevalence of $89.47 \%$ (323 teachers), against 10.53\% (38) of male teachers. Data on age distribution are shown in - Fig. $\mathbf{1}$.

In total, 20 (5.54\%) teachers reported smoking habits, and 150 teachers $(41.55 \%)$ reported alcohol intake. Among these 150 teachers (100\%), 42 (28\%) reported alcohol intake once or more than once a week, and 108 (72\%) reported alcohol intake sporadically or only socially.

Regarding the years of professional experience, 47 teachers (13.02\%) reported having less than 5 years; 43 (11.91\%), between 5 and 9 years; 172 (47.65\%), between 10 and 19 years; 89 (24.65\%), between 20 and 29 years; and $10(2.77 \%)$, between 30 and 39 years.

Regarding the grade taught, 59 (16.34\%) teachers worked in pre-school; 241 (66.76\%), in elementary and middle school; 41 (11.36\%), in high school; 15 (4.16\%), in special education; and 5 (1.38\%), in technical education.

The voice complaints reported by the teachers are presented in - Fig. 2.

-Fig. 3 shows the duration of the main voice complaint reported.

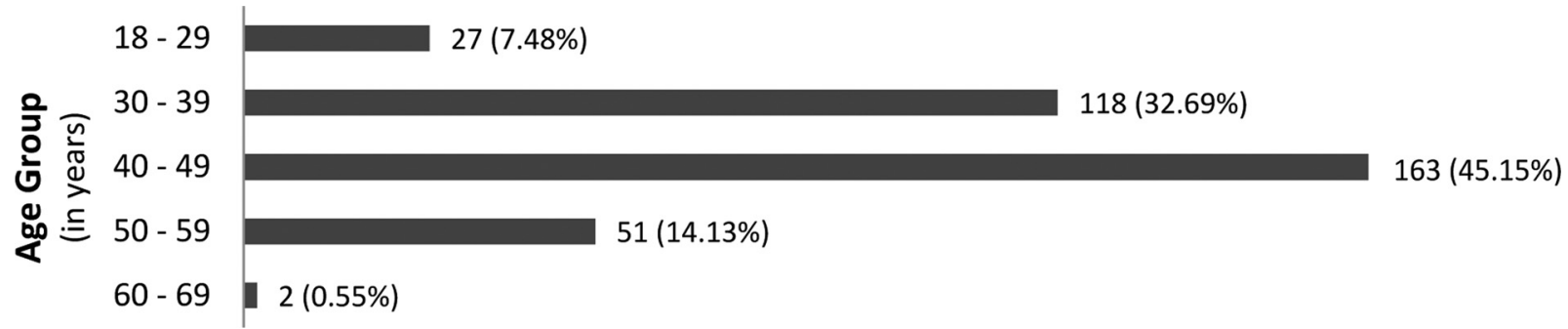

Fig. 1 Distribution of the sample $(N=361)$ by age group (in years).

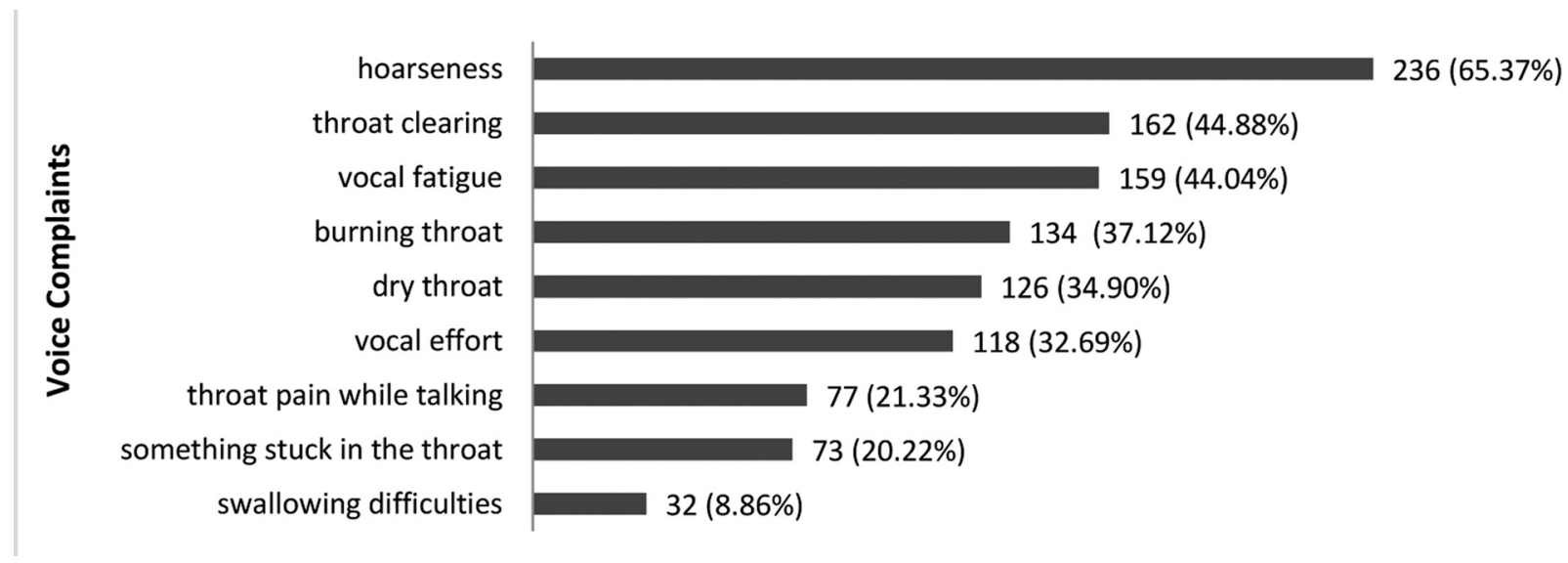

Fig. 2 Distribution of the teachers with one or more voice complaints $(N=361)$. 


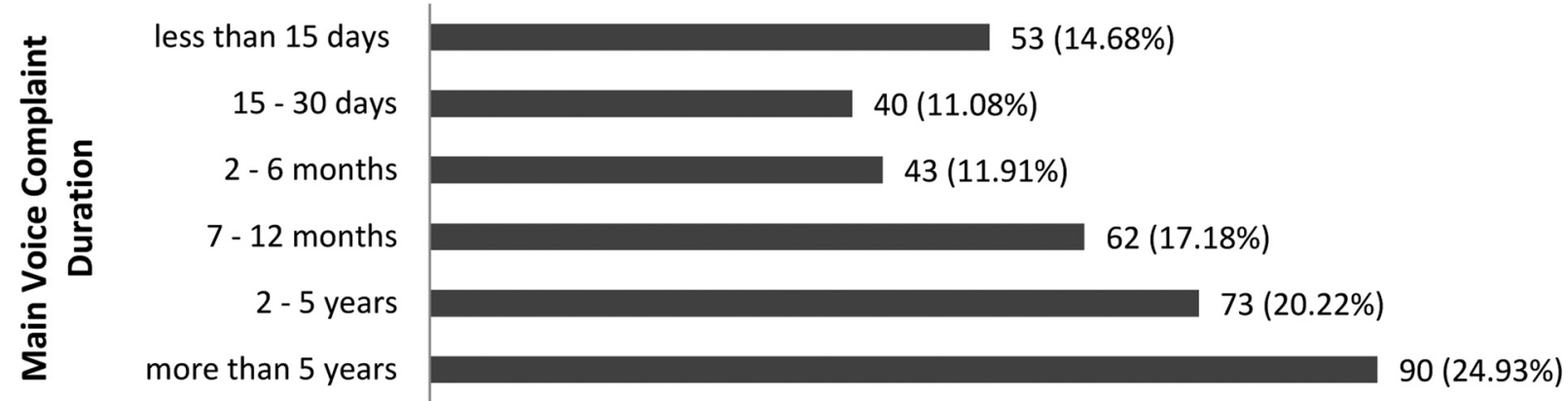

Fig. 3 Distribution of the sample regarding the duration of the main voice complaint $(N=361)$.

Regarding the degree of dysphonia observed during the vocal screening, 98 (27.15\%) teachers presented mild dysphonia; 221 (61.22\%), moderate dysphonia; and 42 (11.63\%), severe dysphonia.

In the laryngeal screening, 269 teachers (74.52\%) presented laryngeal disorders, and in 92 (25.48\%) the findings were normal. The findings on laryngeal disorders are presented in - Fig. 4.

As some teachers presented more than one laryngeal disorder, they also received more than one type of referral after the screening. The referrals made are presented in - Fig. $\mathbf{5}$.

The results of the assessment of vocal aptitude for work was based on the vocal and videolaryngoscopy findings, and it was only added to the documents of the VHP in 2015.
Therefore, -Fig. 6 shows these results regarding only the teachers who met the inclusion criteria in $2015(N=166)$.

\section{Discussion}

The present study analyzed the assessment forms of 361 teachers who took part in the VHP.

A minimum rate of $27.78 \%$ of dysphonia was observed among the teachers, which shows the importance of the auditoryperceptual analysis of voice. Although subjective, this analysis proves to be an important tool to detect voice disorders.

The results showed a predominance of dysphonia among female teachers (89.47\%), which corroborates the findings of other authors. ${ }^{4,13,17-19}$ A possible explanation for the female

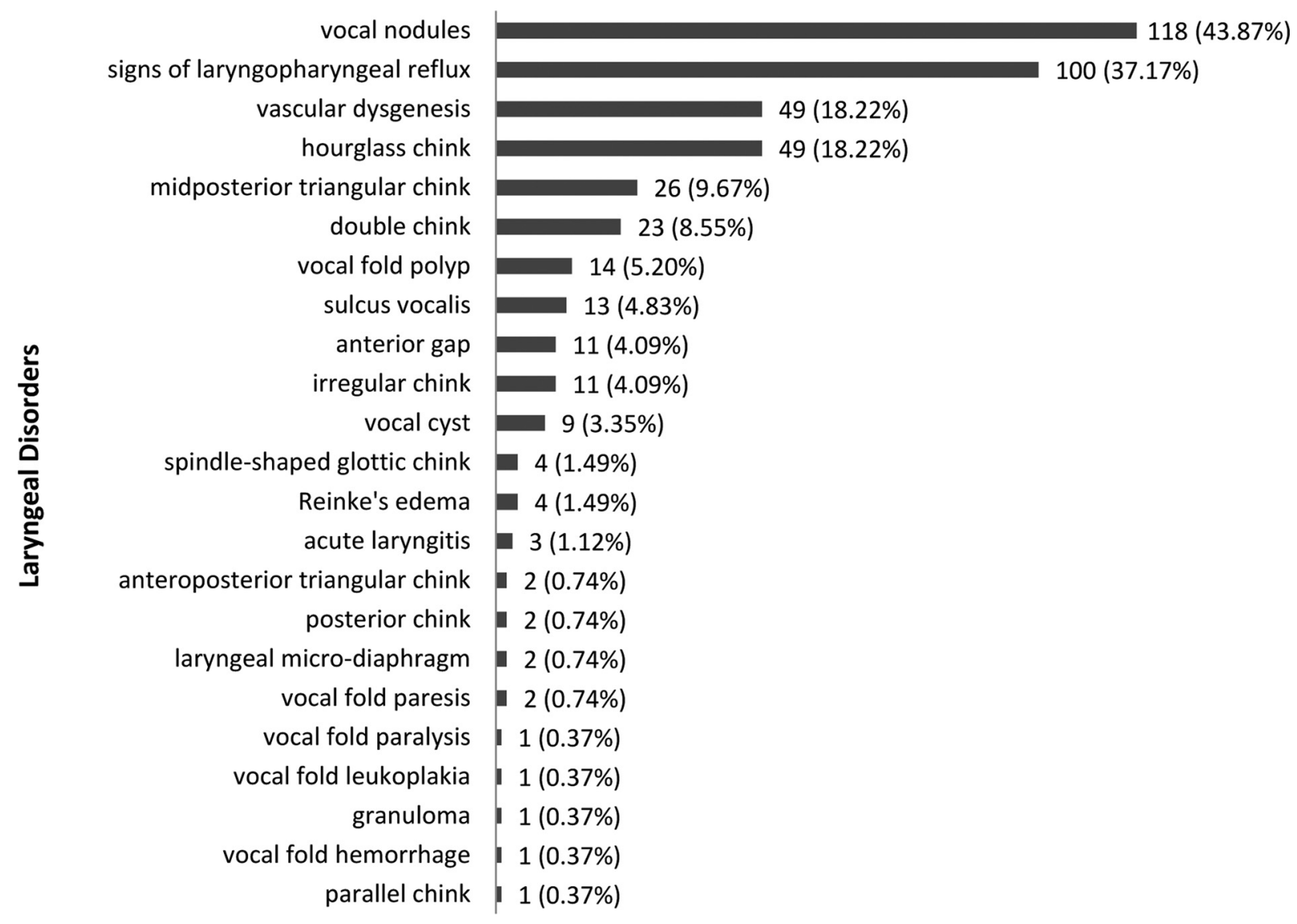

Fig. 4 Distribution of the teachers with one or more laryngeal disorders $(N=269)$. 


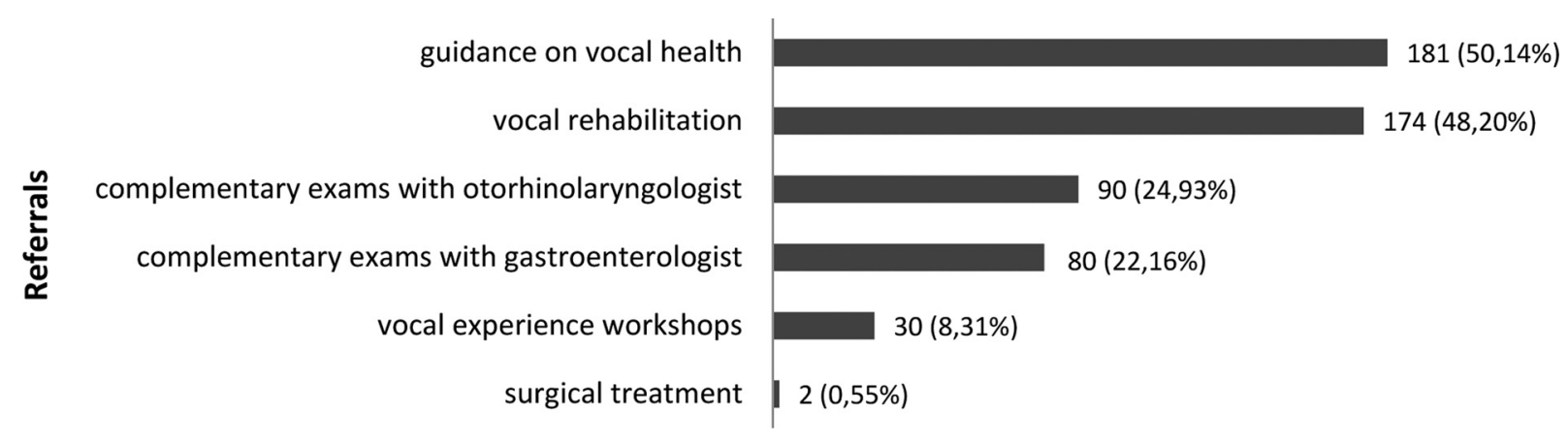

Fig. 5 Distribution of the sample regarding the referrals after the laryngeal screening $(N=361)$.
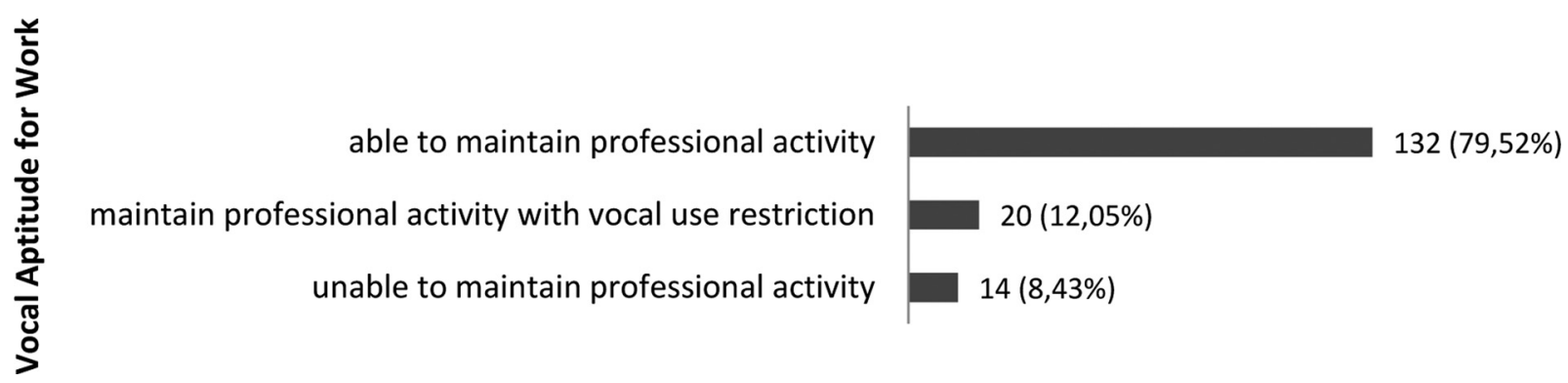

Fig. 6 Distribution of the sample evaluated in 2015 regarding the result of the assessment of vocal aptitude for work $(N=166)$.

predominance lie in the greater concern of women with their vocal quality, in the greater number of women working as teachers, and in the greater adherence of women to continuing education programs. The predominance can also be justified by the anatomical particularities of the lamina propria in women, due to an irregular distribution in the concentration of hyaluronic acid ${ }^{20}$, and by the glottic proportion of $1: 1$ in female larynx. ${ }^{2}$

Regarding age, there was a predominance of the age groups of 40 to 49 years $(45.15 \%)$ and 30 to 39 years (32.69\%), ages of intense professional activity, similar to that found by Smith et al., ${ }^{12}$ in whose study most of the teachers who reported vocal symptoms were 40 years old on average.

Regarding smoking and drinking habits, we observed a low percentage of smoking (5.54\%) and of alcohol intake one or more times a week (11.63\%). In a study ${ }^{4}$ performed in the United States with teachers with and without voice disorders, the percentage found was higher; $\sim 24 \%$ of teachers declared themselves as smokers, and $34.1 \%$ declared they ingested alcoholic beverages one or more times a week.

Considering the years of professional experience, we observed teachers with dysphonia in every group, with a predominance amobg those with 10 to 19 years of professional experience (47.65\%). In spite of this finding, , there isn't in the literature a stablished relationship between the years of professional experience and the risk of developing voice disorders. ${ }^{9,11,12,21}$ The findings of dysphonia early in the teaching career may be due to the lack of preparation for the high phonatory demand and the lack of knowledge about preventive measures regarding voice care. Many teachers have vocal symptoms and laryngeal disorders even before starting their teaching careers. Ohlsson et al. ${ }^{6}$ interviewed 1,250 students, and identified vocal symptoms in $17 \%$ of them. Among pedagogy students, Simberg et al. ${ }^{3}$ identified voice disorders in $20 \%$ of the students interviewed, reinforcing the necessity of laryngeal exams upon the admission of teachers, and the adoption of preventive vocal measures. The data from the present study also reinforce the necessity of a periodic assessment of the teachers' vocal quality.

The grade taught by the teacher can also influence vocal demand. Some authors emphasize that the pedagogical activities from the early stages of pre-school to elementary and middle school require greater vocal demand. ${ }^{22,23}$ Preschool, elementary school, and middle school teachers have more vocal symptoms than higher-education teachers. ${ }^{24,25}$ The results of the present study are in line with this information: we found a relevant percentage of elementary school and middle school teachers (66.76\%), followed by pre-school teachers (16.34\%) and high school teachers (11.36\%). In contrast, only $1.38 \%$ of the teachers worked in technical education.

The voice complaints most frequently reported by the teachers in the present study were hoarseness, throat clearing, vocal fatigue, burning throat, dry throat, and vocal effort, corroborating the main complaints found in other studies. $^{4,6,8-10,12}$

About $62 \%$ of the teachers reported voice complaints for more than 6 months. However, it was not possible to know if the teachers sought professional assistance during this period, because the assessment form did not contain any blanks referring to the search for professional assistance after the 
complaint appeared. Many of these symptoms are directly related to the high phonatory demand, and are more frequent among teachers. ${ }^{4,8,12}$ The chronic course of symptoms shows that vocal impairment is gradual and progressive. Often, vocal symptoms fluctuate throughout the day. They get worse at the end of the day and ameliorate with vocal rest. Dysphonia is initially sporadic, and becomes permanent over the years, with the appearance of laryngeal disorders.

Regarding the degree of dysphonia, 221 (61.22\%) teachers in the sample presented moderate dysphonia, a percentage much higher than that described by Pereira ${ }^{15}$ in a study, using GRBASI (Grade, Roughness, Breathiness, Asthenia, Strain and Instability) scale, conducted with 90 dysphonic teachers in which mild dysphonia was found in most participants (62.22\%). This can be explained by the criterion adopted by the VHP of only referring teachers with mild dysphonia who reported a previous history of laryngeal disorders. Therefore, only part of the teachers identified with mild dysphonia by the VHP in 2014 and 2015 participated in the present study.

Another finding of the present study was the identification of laryngeal disorders in $74.52 \%$ of sample. The videolaryngoscopy exam is essential to confirm the diagnosis of dysphonia. However, in most studies, it has not been included in the methodology. Among the 500 publications on vocal disorders in teachers identified by Dragone et al., ${ }^{26} 15.3 \%$ included auditory-perceptual analysis of voice, $4.9 \%$ included acoustic analysis of voice, and only $4.7 \%$ presented the results of laryngoscopy exams.

Regarding the laryngeal disorders observed on videolaryngoscopy, Van Houtle et al. ${ }^{18}$ found $15 \%$ of vocal nodules and $11 \%$ of gastroesophageal reflux in the teachers examined in their study. Pereira identified $34.4 \%$ of vocal nodules among dysphonic teachers. ${ }^{15}$ A high rate of vocal nodules (43.87\%) was also found in the present study. It is noteworthy that both midposterior triangular chink and double chink, findings of the present study, are generally related to the presence of vocal nodules and to musculoskeletal tension syndrome, and the literature shows that the midposterior triangular chink precedes the formation of vocal nodules. ${ }^{27}$ The pathophysiology of vocal nodules is directly related to vocal abuse and high phonatory demand. The few periods of vocal rest between teaching activities interfere with the reabsorption of the subepithelial edema formed during the constant collisions between the vocal folds. Histological and immunohistochemical studies ${ }^{28,29}$ of vocal nodules reveal important epithelial hyperplasia, thickening of the basement membrane, edema, and fibrosis in the lamina propria, as well as an increase in fibronectin, an important glycoprotein with adhesion and repair functions, indicating that it is a phonotraumatic lesion.

Another relevant laryngeal disorder observed in the present study were signs of laryngopharyngeal reflux. This diagnosis was attributed to the presence of mucosal thickening, pachydermia in the interarytenoid region, and arytenoid hyperemia. The symptoms of laryngopharyngeal reflux associated with these laryngeal disorders lead to the diagnosis of acid laryngitis, although the classic symptoms of heartburn and regurgitation of gastric content are not always present in extraesophageal reflux. In these patients, even esophageal $\mathrm{pH}$ tests can be within the normal range. However, the fact that many individuals benefit from treatment with proton-pump inhibitors and dietary guidelines demonstrates the importance of a conjoint treatment of laryngopharyngeal reflux in dysphonic patients. ${ }^{30-32}$

Vocal-fold polyps, cysts, and sulcus vocalis were also important videolaryngoscopy findings of the present study. Vocal-fold polyps represent mucosal lesions secondary to inflammatory and allergic processes, and can originate from vocal abuse. Reports of recurrent inflammatory conditions in the upper airways, such as rhinitis, allergies, laryngopharyngeal reflux, and chronic cough are frequent in patients with vocal fold polyps. The importance of investigating these symptoms in dysphonic patients is emphasized. ${ }^{15}$ Sulcus vocalis, vascular dysgenesis, and vocal cysts are congenital lesions, and their degree of adherence to the vocal ligament determines the extent of the vocal impairment. ${ }^{33}$

After the laryngeal screening, most teachers in the present study were referred for guidance on vocal health and vocal rehabilitation. Less than $1 \%$ of teachers needed referrals for immediate surgical treatment. Even with vocal and laryngeal disorders, $79.52 \%$ of the teachers were considered able to maintain their professional activity because, with their participation in the VHP, they obtained information about their vocal and laryngeal diagnoses, and about voice care, and are now able to perform their professional activities with greater vocal awareness.

\section{Conclusion}

The results of the present study showed that working as a teacher is a risk factor for the development of voice disorders. Furthermore, it showed that dysphonia, observed during the auditory-perceptual screening of the voice, is also a risk variable for the presence of laryngeal disorders, reiterating that laryngeal screening through videolaryngoscopy in vocal health programs is fundamental to define the diagnosis and therapeutic conduct of teachers with dysphonia.

These data reinforce the importance and the necessity of: intervention activities; continuing education for prevention and the dissemination of knowledge; active search for diagnosis; periodic evaluation of vocal health; adequate and accessible treatment and monitoring. Such actions can contribute to reduce absenteeism and improve the quality of life and of the voice of teachers.

\section{Conflict of Interests}

Dr. Granjeiro reports personal fees from the State Departments of Education and of Health of the Government of the Brazilian Federal District outside the submitted work.

Dr. Dias reports personal fees from the State Department of Health of the Government of the Brazilian Federal District outside the submitted work.

Dr. Cristiane Ferraz de Oliveira and Dr. Glaucia Mara Gomes Ferreira Oliveira report personal fees from the State Department of Education of the Government of the Brazilian Federal District outside the submitted work. 
Dr. Lorena Cássia de Carvalho Oliveira has no conflict of interests to declare.

\section{References}

1 Sataloff RT. Professional voice: the science and art of clinical care. 3rd ed. San Diego: Plural Publishing; 2005

2 Caldas Neto S, Mello Júnior JF, Martins RHG, Costa SS. Tratado de Otorrinolaringologia. vol. IV. São Paulo: Roca; 2011

3 Simberg S, Laine A, Sala E, Rönnemaa AM. Prevalence of voice disorders among future teachers. J Voice 2000;14(02):231-235

4 Roy N, Merrill RM, Thibeault S, Gray SD, Smith EM. Voice disorders in teachers and the general population: effects on work performance, attendance, and future career choices. J Speech Lang Hear Res [Internet]. 2004 Jun;47(3):542-51. Accessed Sep 9, 2020 at: https://pubs.asha.org/doi/10.1044/1092-4388(2004/042

5 Simões M, Latorre MdoR. [Prevalence of voice alteration among educators and its relationship with self-perception]. Rev Saude Publica 2006;40(06):1013-1018http://www.scielo.br/scielo.php? script $=$ sci_arttext $\&$ pid $=$ S0034-89102006000700008\&lng=en Accessed Sep92020 [Internet]

6 Ohlsson AC, Andersson EM, Södersten M, Simberg S, Barregård L. Prevalence of voice symptoms and risk factors in teacher students. J Voice 2012;26(05):629-634

7 Behlau M, Zambon F, Guerrieri AC, Roy N. Epidemiology of voice disorders in teachers and nonteachers in Brazil: prevalence and adverse effects. J Voice 2012;26(05):665.e9-665.e18

8 Tavares ELM, Martins RHG. Vocal evaluation in teachers with or without symptoms. J Voice 2007;21(04):407-414

9 Chen SH, Chiang SC, Chung YM, Hsiao LC, Hsiao TY. Risk factors and effects of voice problems for teachers. J Voice 2010;24(02):183-190, quiz 191-192https://www.sciencedirect.com/science/article/abs/pii/ S0892199708001240 Accessed Sep92020 [Internet]

10 Lima-Silva MFB, Ferreira LP, Oliveira IB, Silva MAA, Ghirardi ACAM. Voice disorders in teachers: self-report, auditory-perceptive assessment of voice and vocal fold assessment. Rev Soc Bras Fonoaudiol 2012;17(04):391-397 Accessed Sep 9, 2020 [Internet] at http:// www.scielo.br/scielo.php?script=sci_arttext\&pid=S1516-8034201 2000400005\&lng $=$ en

11 Fuess VLR, Lorenz MC. Vocal problems in kindergarten and primary school teachers: prevalence and risk factors. Braz J Otorhinolaryngol 2003;69(06):807-812

12 Smith E, Kirchner HL, Taylor M, Hoffman H, Lemke JH. Voice problems among teachers: differences by gender and teaching characteristics. J Voice 1998;12(03):328-334

13 Angelillo M, Di Maio G, Costa G, Angelillo N, Barillari U. Prevalence of occupational voice disorders in teachers. J Prev Med Hyg 2009; 50(01):26-32

14 Da Costa V, Prada E, Roberts A, Cohen S. Voice disorders in primary school teachers and barriers to care. J Voice 2012;26(01): 69-76https://www.jvoice.org/article/S0892-1997(10)00161-X/ fulltext Accessed Sep92020 [Internet]

15 Pereira ERBN. Avaliação clínica, videolaringoscópica e vocal perceptivo-auditiva e acústica de professores disfônicos [thesis]. Botucatu: Universidade Estadual Paulista Júlio de Mesquita Filho; 2014:95. Accessed Sep 9, 2020 at: http://hdl.handle.net/11449/114043
16 Oliveira GMGF, Oliveira CF, Melo DC, Carvalho WKC, Martins LCCS, Granjeiro RC. Programa de saúde vocal: primeiro olhar para os professores das escolas públicas do Distrito Federal. In: Ferreira LP, Silva MAA, Giannini SPP, editors. Distúrbio de voz relacionado ao trabalho: práticas fonoaudiológicas. São Paulo: Roca; 2015:47-58

17 Amorim AL, Robazzi MLCC, Marziale MHP, Felippe ACN, Romano CC. Health disorders and teachers' voices: a workers' health issue. Rev Latino-Am Enfermagem [Internet]. 2009 Aug;17(4):566-72. Accessed Sep 9, 2020 at: $h t t p: / / w w w . s c i e l o . b r / s c i e l o . p h p ? s c r i p t=$ sci_arttextEpid=S0104-11692009000400020Elng=en

18 Van Houtte E, Van Lierde K, D'Haeseleer E, Claeys S. The prevalence of laryngeal pathology in a treatment-seeking population with dysphonia. Laryngoscope 2010;120(02):306-312

19 Souza CL, Carvalho FM, Araújo TM, Reis EJFB, Lima VM, Porto LA. Factors associated with vocal fold pathologies in teachers. Rev Saude Publica 2011;45(05):914-921

20 Butler JE, Hammond TH, Gray SD. Gender-related differences of hyaluronic acid distribution in the human vocal fold. Laryngoscope 2001;111(05):907-911

21 Bassi IB, Assunção AA, Gama ACC, Gonçalves LG. Características clínicas, sociodemográficas e ocupacionais de professoras com disfonia. Distúrb Comun 2011;23(02):173-180

22 Sarfati J. [Vocal retraining of teachers]. Rev Laryngol Otol Rhinol (Bord) 1989;110(04):393-395

23 Mattiske JA, Oates JM, Greenwood KM. Vocal problems among teachers: a review of prevalence, causes, prevention, and treatment. J Voice 1998;12(04):489-499

24 Bovo R, Galceran M, Petruccelli J, Hatzopoulos S. Vocal problems among teachers: evaluation of a preventive voice program. J Voice 2007;21(06):705-722

25 Munier C, Kinsella R. The prevalence and impact of voice problems in primary school teachers. Occup Med (Lond) 2008;58(01): 74-76 https://academic.oup.com/occmed/article/58/1/74/1536038 Accessed Sep92020 [Internet]

26 Dragone MLS, Ferreira LP, Giannini SPP, Simões-Zenari M, Vieira VP, Behlau M. Teachers' voice: a review of 15 years of SLP contribution. Rev Soc Bras Fonoaudiol 2010;15(02):289-296

27 Behlau M. Voz: o livro do especialista. vol I São Paulo: Revinter; 2001

28 Remacle M, Degols JC, Delos M. Exudative lesions of Reinke's space. An anatomopathological correlation. Acta Otorhinolaryngol Belg 1996;50(04):253-264

29 Martins RH, Defaveri J, Custódio Domingues MA, de Albuquerque E Silva R, Fabro A. Vocal fold nodules: morphological and immunohistochemical investigations. J Voice 2010;24(05):531-539

30 Martins RH, Branco A, Tavares EL, Iyomasa RM, Carvalho LR, Henry MA. Laryngeal and voice disorders in patients with gastroesophageal symptoms. Correlation with $\mathrm{pH}-$ monitoring. Acta Cir Bras 2012;27(11):821-828

31 Hawkshaw MJ, Pebdani P, Sataloff RT. Reflux laryngitis: an update, 2009-2012. J Voice 2013;27(04):486-494https://www.jvoice.org/article/S0892-1997(13)00047-7/fulltext Accessed Sep92020 [Internet]

32 Hom C, Vaezi MF. Extra-esophageal manifestations of gastroesophageal reflux disease: diagnosis and treatment. Drugs 2013;73(12):1281-1295

33 Pontes P, Behlau M. Sulcus mucosal slicing technique. Curr Opin Otolaryngol Head Neck Surg 2010;18(06):512-520 